\title{
Effects of Rapid Thermal Annealing on the Structural, Optical, and Electrical Properties of $\mathrm{ZnO} / \mathrm{Ag} / \mathrm{SnO}_{2}$ Tri-Layer Films
}

\author{
Su-Hyeon Choe ${ }^{1}$, Yu-Sung Kim ${ }^{1,2}$, Jin-Young Choi ${ }^{1}$, Yun-Je Park ${ }^{1}$, \\ Byung-Chul Cha ${ }^{2}$, Young-Min Kong ${ }^{1}$, and Daeil Kim ${ }^{1, *}$ \\ ${ }^{1}$ School of Materials Science and Engineering, University of Ulsan, Ulsan 44776, Republic of Korea \\ ${ }^{2}$ Advanced Forming Processes R\&D Group, Ulsan Regional Division, Korea Institute of Industrial Technology, \\ Ulsan 44413, Republic of Korea
}

\begin{abstract}
ZnO} 50 \mathrm{~nm} / \mathrm{Ag} 10 \mathrm{~nm} / \mathrm{SnO}_{2} 50 \mathrm{~nm}$ (ZAS) tri-layer films were deposited on a glass substrate by RF and DC magnetron sputtering and then underwent rapid thermal annealing in a low vacuum of $1 \times 10^{-3}$ Torr to investigate the effects of post-deposition annealing on the optical and electrical properties of the films. The peak intensity of the XRD pattern related to the $\mathrm{ZnO}(002)$ peak of the annealed films was higher than that of the as-deposited film and the full width at half-maximum of the $\mathrm{ZnO}(002)$ diffraction peak of the annealed films was smaller than that of the as-deposited film. Therefore, the crystallinity of $\mathrm{ZnO}$ was improved by rapid annealing. However, crystallization of the Ag interlayer and $\mathrm{SnO}_{2}$ surface layer were not significantly affected by the annealing temperature, compared with the $\mathrm{ZnO}$ bottom layer. From the observed electrical properties and optical band gap, it was concluded that the blue shift in the optical band gap is related to the carrier density of the films. The band gap increased from $4.19 \mathrm{eV}$ to $4.24 \mathrm{eV}$, with the carrier density increasing from $7.09 \times 10^{21} \mathrm{~cm}^{-3}$ to $7.77 \times 10^{21} \mathrm{~cm}^{-3}$. However, the film annealed at $450{ }^{\circ} \mathrm{C}$ showed a decreased band gap energy of $4.17 \mathrm{eV}$ due to the decreased carrier density of 6.80 $\times 10^{21} \mathrm{~cm}^{-3}$. The as-deposited ZAS films showed a sheet resistance of $11.0 \Omega / \square$ and a visible transmittance of $80.8 \%$, whereas the films annealed at $450{ }^{\circ} \mathrm{C}$ had a higher visible transmittance of $82.3 \%$ and a lower sheet resistance of 6.55 $\Omega / \square$. The results indicate that ZAS thin films may be possible substitutes for conventional Sn-doped $\operatorname{In}_{2} \mathrm{O}_{3}$ transparent electrodes in various optoelectronic devices.
\end{abstract}

(Received May 13, 2019; Accepted June 20, 2019)

Keywords: $\mathrm{ZnO} / \mathrm{Ag} / \mathrm{SnO}_{2}$, magnetron sputtering, annealing, AFM, XRD.

\section{INTRODUCTION}

Various transparent conductive oxide (TCO) films such as Sn-doped $\mathrm{In}_{2} \mathrm{O}_{3}$ (ITO) and Ga-doped $\mathrm{ZnO}$ (GZO) thin films are being used as transparent electrodes for large displays and thin-film solar cells [1,2]. Although conventional ITO thin film has high visible transmittance and low electrical resistivity, its optoelectrical applications are limited due to the rarity of indium (In), its poor mechanical properties, and chemical instabilities [3]. Thus, in recent years new metal oxide/metal/metal oxide (OMO) tri-layer films such as TiON/Au/TiON [4], ZTO/Ag/ZTO [5], and IGZO/Ni/IGZO [6] have been developed in the

- 최수현, 최진영, 박윤제: 석사과정, 김유성, 차병철: 연구원, 김대일, 공영민: 교수 *Corresponding Author: Daeil Kim

[Tel: +82-52-712-8066, E-mail: dkim84@ulsan.ac.kr]

Copyright (c) The Korean Institute of Metals and Materials search for suitable candidates to replace conventional ITO films.

In this study, we propose the use of $\mathrm{ZnO} / \mathrm{Ag} / \mathrm{SnO}_{2}$ (ZAS) tri-layered films, with $50 \mathrm{~nm}$ thick $\mathrm{ZnO}$ and $\mathrm{SnO}_{2}$ thin films used as the metal oxide layers due to their mechanical hardness, abundance, chemical stability, and thermal stability; and $10 \mathrm{~nm}$ thick $\mathrm{Ag}$ thin film used as a metallic interlayer to act as an effective charge carrier. To investigate the optical and electrical properties of the films, $\mathrm{ZnO} 50 \mathrm{~nm} /$ $\mathrm{Ag} 10 \mathrm{~nm} / \mathrm{SnO}_{2} 50 \mathrm{~nm}$ films were deposited by RF and DC magnetron sputtering and then compared with a $100 \mathrm{~nm}$ thick $\mathrm{SnO}_{2}$ single layer film.

In addition, it is well known that post-deposition annealing of high quality TCO preparations increases their optical transmittance and electrical conductivity by enhancing the crystallinity of the films $[8,9]$. Thus, the 
effects of rapid thermal annealing in a low vacuum condition on the optical and electrical properties of the ZAS films was also investigated.

\section{EXPERIMENTAL PROCEDURES}

$\mathrm{ZnO} 50 \mathrm{~nm} / \mathrm{Ag} 10 \mathrm{~nm} / \mathrm{SnO}_{2} 50 \mathrm{~nm}$ tri-layer films and 100 $\mathrm{nm}$ thick $\mathrm{SnO}_{2}$ single-layer films were deposited on a glass substrate (Corning 1797, $30 \times 30 \mathrm{~mm}^{2}$ ) by RF and DC magnetron sputtering at room temperature, followed by postdeposition annealing, to compare their optical and electrical properties. Table 1 shows the experimental conditions of the magnetron sputtering and rapid thermal annealing (RTA) processes. The deposition rate and thickness of the films were measured with a surface profilometer (Dektak 500, Veeco). The surface roughness was evaluated via atomic force microscopy (XE-100, PSIA). A depth profile analysis was conducted with X-ray photoelectron spectroscopy at the Korea Basic Science Institute Busan center to observe the stacking structure of the film.

After post-deposition RTA, thin film crystallization was investigated with high-resolution X-ray diffraction (XRD; X'Pert Pro MRD, Philips) using $\mathrm{Cu}-\mathrm{K} \alpha$ (0.154 nm) radiation. Optical transmittance (wavelength: 380-780 nm) and electrical properties such as the sheet resistance, carrier density and mobility of the films were measured with an ultraviolet-visible spectrophotometer (Cary100 Cone, Varian), four-point probe and Hall-effect measurement system (HMS-3000, Ecopia), respectively.

Table 1. Experimental conditions for $\mathrm{ZnO} / \mathrm{Ag} / \mathrm{SnO}_{2}$ tri-layer films.

\begin{tabular}{cc}
\hline Base pressure (Torr) & $6.0 \times 10^{-7}$ \\
\hline Deposition pressure (Torr) & $1.0 \times 10^{-3}$ \\
\hline Substrate temperature & Room temperature \\
\hline RF sputtering power $\left(\mathrm{W} / \mathrm{cm}^{2}\right)$ & $\mathrm{ZnO}: 6.0, \mathrm{SnO}_{2}: 2.5$ \\
\hline DC sputtering power $\left(\mathrm{W} / \mathrm{cm}^{2}\right)$ & $\mathrm{Ag}: 1.6$ \\
\hline Ar gas flow rate $(\mathrm{sccm})$ & 10 \\
\hline Film thickness $(\mathrm{nm})$ & 100 \\
$\mathrm{SnO}_{2}$ single layer & $50 / 10 / 50$ \\
$\mathrm{ZnO}^{2} \mathrm{Ag} / \mathrm{SnO}_{2}$ & $150,300,450$ \\
\hline Annealing temperature $\left({ }^{\circ} \mathrm{C}\right)$ & $1 \times 10^{-3} / 5$
\end{tabular}

\section{RESULTS AND DISCUSSION}

Figure 1 shows the X-ray photoelectron spectroscopy depth profile of as-deposited ZAS films, which consisted of tin $(\mathrm{Sn})$ and oxygen at the surface, silver $(\mathrm{Ag})$ in the middle, and zinc $(\mathrm{Zn})$ and oxygen on the bottom.

Figure 2 shows the XRD patterns of the as-deposited (Fig. 2a) and the rapid thermal annealed ZAS films (Figs. 2b-d). The observed diffraction peaks are related to the $\mathrm{ZnO}$ (JCPDS card; 36-1451) and the bottom layer and Ag (JCPDS card; 87-0719) interlayer, respectively. The XRD pattern indicated that the $\mathrm{ZnO}$ films had a $\mathrm{C}$-axis orientation. The peak intensity of the XRD pattern related to the $\mathrm{ZnO}(002)$

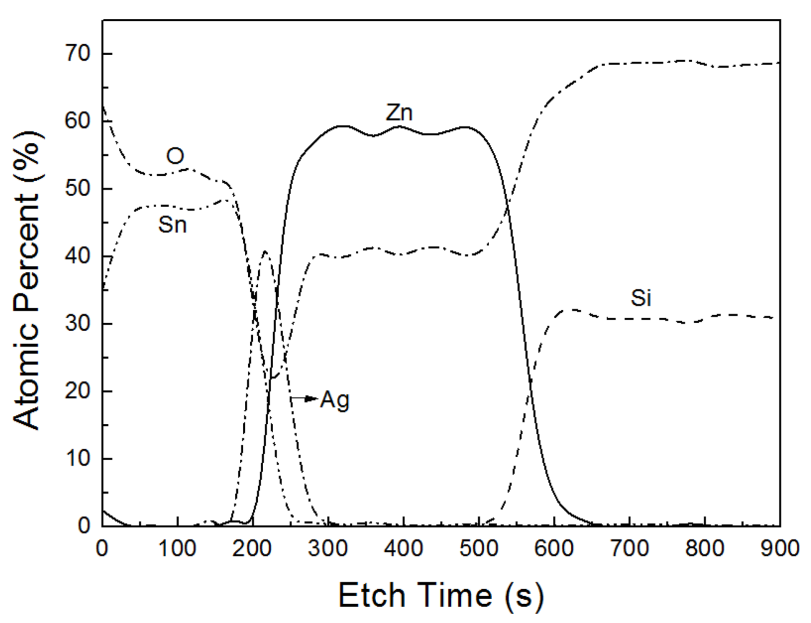

Fig. 1. The XPS depth profile of as-deposited ZAS film.

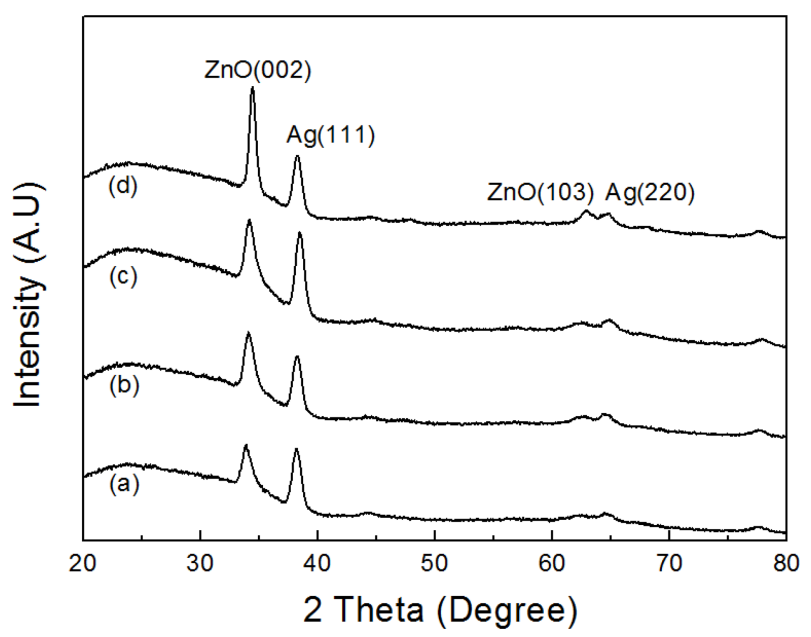

Fig. 2. $\mathrm{XRD}$ pattern of $\mathrm{ZnO} / \mathrm{Ag} / \mathrm{SnO}_{2}$ tri-layer films as a function of the annealing temperature. (a) as deposited film, (b) annealed film at $150{ }^{\circ} \mathrm{C}$, (c) annealed film at $300^{\circ} \mathrm{C}$, (d) annealed film at $450^{\circ} \mathrm{C}$. 
Table 2. The grain size (nm) of ZAS films as a function of annealing temperature

\begin{tabular}{ccccc}
\hline & $\begin{array}{c}\text { As } \\
\text { deposition }\end{array}$ & $150{ }^{\circ} \mathrm{C}$ & $\begin{array}{c}\text { Annealing } \\
300{ }^{\circ} \mathrm{C}\end{array}$ & $450{ }^{\circ} \mathrm{C}$ \\
\hline $\mathrm{ZnO}(002)$ & 9.6 & 9.7 & 11.2 & 13.4 \\
$\mathrm{Ag}(111)$ & 9.7 & 9.7 & 9.4 & 9.4 \\
\hline
\end{tabular}

peak of the annealed films was higher than that of the asdeposited film; in addition, the full width at half-maximum (FWHM) of the $\mathrm{ZnO}$ (002) diffraction peak for the annealed films was smaller than that of the as-deposited $\mathrm{ZnO}$ film. Therefore, the crystallinity of the $\mathrm{ZnO}$ was improved by rapid annealing [7].

However, crystallization of the $\mathrm{Ag}$ interlayer and $\mathrm{SnO}_{2}$ surface layer were not significantly affected by the annealing temperature, compared with the $\mathrm{ZnO}$ bottom layer. As shown in Fig. 2, the annealed films did not show any change in the FWHM of the Ag (111) diffraction peak; furthermore, no diffraction peaks related to the $\mathrm{SnO}_{2}$ film can be observed in the XRD pattern. Therefore, the 50-nm-thick $\mathrm{SnO}_{2}$ upper film remained amorphous regardless of the annealing temperature.

Table 2 shows the grain size of both the $\mathrm{ZnO}(002)$ and $\mathrm{Ag}$ (111) planes as evaluated by the Scherrer equation [7]. The grain size of the $\mathrm{ZnO}$ bottom layer increased proportionally to the annealing temperature. In a previous study, Kim [8] reported that the optical and electrical properties of TCO films depended on the crystallinity of the films, because the grain boundary can simultaneously absorb visible light and decrease carrier mobility. Because enlarged grain size results in a decreased absorption of visible light, the visible transmittance of the films is expected to increase with

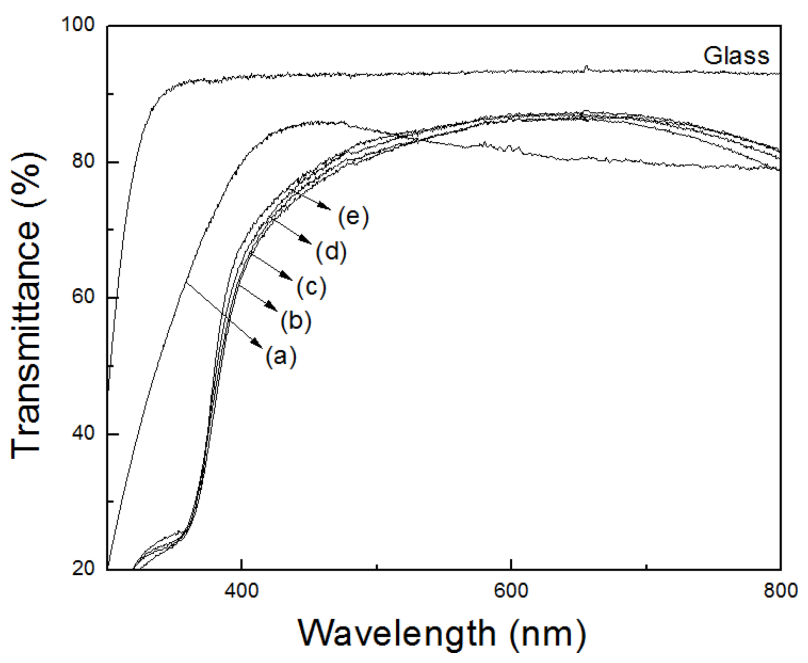

Fig. 3. Optical transmittance of the $\mathrm{ZnO} / \mathrm{Ag} / \mathrm{SnO}_{2}$ tri-layer films. (a) as deposited $\mathrm{SnO} 2$ film, (b) as deposited ZAS films, (c) annealed ZAS films at $150{ }^{\circ} \mathrm{C}$, (d) annealed ZAS films at $300{ }^{\circ} \mathrm{C}$, (d) annealed ZAS films at $450{ }^{\circ} \mathrm{C}$.

annealing temperature.

Figure 3 shows the optical transmittance of ZAS films annealed at different temperatures. The average visible transmittance of the as-deposited ZAS films was approximately $80.8 \%$. After annealing at $450{ }^{\circ} \mathrm{C}$, the ZAS films showed an increased transmittance of $82.4 \%$ due to grain growth, as shown Table 2 .

Table 3 shows the electrical properties of the as-deposited $\mathrm{SnO}_{2}$ films and ZAS films as a function of annealing temperature. The films annealed at $450{ }^{\circ} \mathrm{C}$ had the lowest resistivity of $7.0 \times 10^{-5} \Omega \mathrm{cm}$, due to an enhanced carrier mobility of $13.1 \mathrm{~cm}^{2} \mathrm{~V}^{-1} \mathrm{~S}^{-1}$.

Figure 4 shows a plot of $(\alpha h v)^{2}$ in the ZAS films as a function of photon energy. The optical absorption coefficient $(\alpha)$ can be calculated from the following equation (1) [8]:

Table 3. The electrical properties of the $\mathrm{SnO}_{2}$ single layer and the $\mathrm{ZAS}$ tri-later films.

\begin{tabular}{|c|c|c|c|c|c|}
\hline \multirow{2}{*}{ Condition } & \multirow{2}{*}{$\begin{array}{c}\mathrm{SnO}_{2} \\
\text { As deposition }\end{array}$} & \multirow{2}{*}{$\begin{array}{c}\text { ZAS } \\
\text { As deposition }\end{array}$} & \multicolumn{3}{|c|}{ Annealing } \\
\hline & & & $150{ }^{\circ} \mathrm{C}$ & $300{ }^{\circ} \mathrm{C}$ & $450{ }^{\circ} \mathrm{C}$ \\
\hline $\begin{array}{c}\text { Sheet resistance } \\
(\Omega / \square)\end{array}$ & 3650 & 11.0 & 7.0 & 6.5 & 6.3 \\
\hline $\begin{array}{l}\text { Carrier density } \\
\qquad\left(\mathrm{cm}^{-3}\right)\end{array}$ & $5.4 \times 10^{19}$ & $7.0 \times 10^{21}$ & $7.6 \times 10^{21}$ & $7.7 \times 10^{21}$ & $6.8 \times 10^{21}$ \\
\hline $\begin{array}{c}\text { Mobility } \\
\left(\mathrm{cm}^{2} \mathrm{~V}^{-1} \mathrm{~S}^{-1}\right)\end{array}$ & 3.1 & 7.3 & 10.6 & 11.1 & 13.1 \\
\hline $\begin{array}{l}\text { Resistivity } \\
(\Omega \mathrm{cm})\end{array}$ & $3.6 \times 10^{-2}$ & $1.2 \times 10^{-4}$ & $7.7 \times 10^{-5}$ & $7.2 \times 10^{-5}$ & $7.0 \times 10^{-5}$ \\
\hline
\end{tabular}




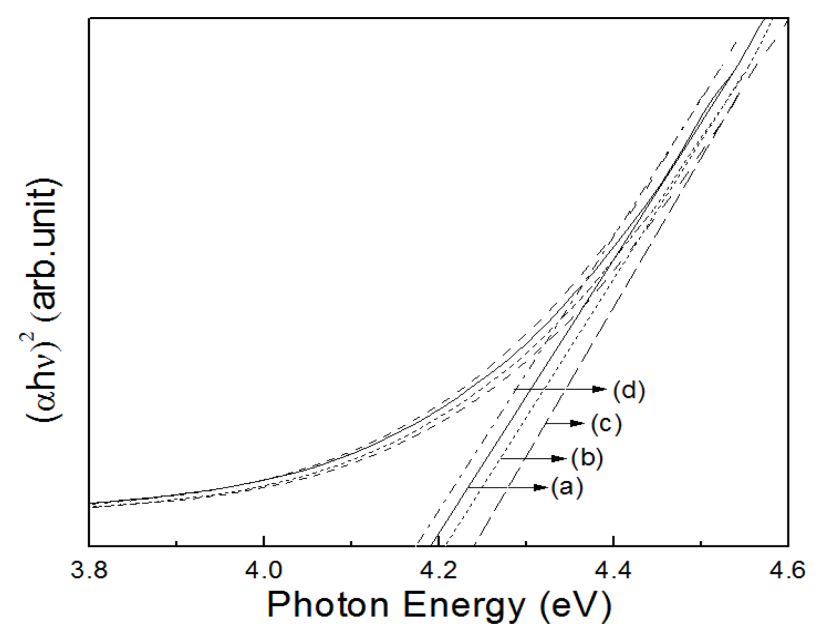

Fig. 4. Plots of $(\alpha h v)^{2}$ as a function of the incident photon energy $(\mathrm{h} v)$ for ZAS films annealed at different temperatures. The extrapolation of the linear region determines optical bandgap $\left(\mathrm{E}_{\mathrm{g}}\right)$ values as indicated with lines. (a) as deposited film; $4.19 \mathrm{eV}$, (b) annealed films at $150{ }^{\circ} \mathrm{C} ; 4.21 \mathrm{eV}$, (c) annealed films at $300{ }^{\circ} \mathrm{C} ; 4.24$ $\mathrm{eV}$, (d) annealed films at $450{ }^{\circ} \mathrm{C} ; 4.17 \mathrm{eV}$.

$$
\alpha=(1 / d) \ln (1 / T)
$$

Here, $d$ is the film thickness and $T$ is the visible transmittance. The Tauc formula (2) gives the relationship between the optical absorption coefficient $(\alpha)$ and optical band gap $\left(\mathrm{E}_{\mathrm{g}}\right)[9]$ :

$$
(\alpha h v)^{2}=A\left(h v-E_{g}\right)
$$

Here, $h v$ is the energy of the incident photon and $A$ is the absorption edge width parameter [10]. In Fig. 4, as the annealing temperature increases to $300{ }^{\circ} \mathrm{C}$, the optical band gap increases proportionally from $4.19 \mathrm{eV}$ (at deposition) to $4.24 \mathrm{eV}$ (at $300{ }^{\circ} \mathrm{C}$ ). From the observed electrical properties and optical band gap, it can be concluded that the broadening of the optical band gap is related to the increased carrier density of the film. The band gap increased from $4.19 \mathrm{eV}$ to $4.24 \mathrm{eV}$, with the carrier density increasing from $7.09 \times 10^{21}$ $\mathrm{cm}^{-3}$ to $7.77 \times 10^{21} \mathrm{~cm}^{-3}$. However, the film annealed at $450{ }^{\circ} \mathrm{C}$ showed a decrease in band gap energy of $4.17 \mathrm{eV}$ due to the decreased carrier density of $6.80 \times 10^{21} \mathrm{~cm}^{-3}$. It is supposed that the surface oxidation decreased the carrier density during thermal annealing at $450{ }^{\circ} \mathrm{C}$. Recently, Tang [10] reported similar results for band gap shift, which depended on the electron density of the GZO thin film.

\section{CONCLUSIONS}

In this study, $\mathrm{ZnO} 50 \mathrm{~nm} / \mathrm{Ag} 10 \mathrm{~nm} / \mathrm{SnO}_{2} 50 \mathrm{~nm}$ (ZAS) trilayer films and $100 \mathrm{~nm}$ thick $\mathrm{SnO}_{2}$ single layer films were deposited by RF and DC magnetron sputtering and then underwent rapid thermal annealing. Measurements were conducted to determine the usefulness of ZAS film as a transparent electrode and the effects of annealing temperature on the structural, optical, and electrical properties of the ZAS films.

As-deposited ZAS films exhibited a visible transmittance of $80.8 \%$, which was comparable to that of $\mathrm{SnO}_{2}$ films but has a lower resistivity of $1.2 \times 10^{-4} \Omega \mathrm{cm}$ compared to $\mathrm{SnO}_{2}$ films. After post-deposition rapid thermal annealing at 450 ${ }^{\circ} \mathrm{C}$, ZAS films showed an enhanced optical transmittance of $82.4 \%$ and a lower resistivity of $7.0 \times 10^{-5} \Omega \mathrm{cm}$. The results indicate that rapid thermal annealed ZAS film with a $10 \mathrm{~nm}$ thick Ag interlayer is a possible candidate for use as a transparent electrode in various display devices.

\section{REFERENCES}

1. S. B. Koo, C. M. Lee, S. J. Kwon, J. M. Jeon, J. Y. Hur, and H. K. Lee, Met. Mater. Int. 25, 117 (2019).

2. H. S. Kim and S. J. Kim, Korean J. Met. Mater. 57, 84 (2019).

3. J. J. Jia, A. Yoshimura, Y. Kagoya, N. Oka, and Y. Shigesato, Thin Solid Films 559, 69 (2014).

4. D. Kim, Mater. Lett. 64, 668 (2010).

5. H. Schmidt, T. Winkler, T. Riedl, I. Baumann, H. Flügge, S. Schmale, H. Johannes, T. Rabe, S. Hamwi, and W. Kowalsky, Energy Procedia 31, 110 (2012).

6. Y. Song, T. Eom, S. Heo, J. Cheon, B. Cha, and D. Kim, Mater. Lett. 205, 122 (2017).

7. C. H. Huang, D. Y. Chen, and C. Y. Hsu, Ceram. Inter. 38, 1057 (2012).

8. S. Peng, T. Yao, Y. Yang, K. Zhang, J. Jiang, K. Jin, G. Li, X. Cao, G. Xu, and Y. Wang, Physica B 503, 111 (2016).

9. J. Tauc, Amorphous and Liquid Semiconductors, Plenum, New York (1974).

10. Y. Wang, W. Tang, L. Zhang, and J. Zhao, Thin Solid Films $\mathbf{5 6 5}, 62$ (2014). 